\title{
Dinzelbacher, Peter, Das Fremde Mittelalter. Gottesurteil und Tierprozess
}

\section{Thomas Lienhard}

\section{OpenEdition}

\section{Journals}

Édition électronique

URL : http://journals.openedition.org/ifha/1636

DOI : 10.4000/ifha.1636

ISSN : 2198-8943

\section{Éditeur}

IFRA - Institut franco-allemand (sciences historiques et sociales)

Référence électronique

Thomas Lienhard, «Dinzelbacher, Peter, Das Fremde Mittelalter. Gottesurteil und Tierprozess », Revue de I'IFHA [En ligne], Date de recension, mis en ligne le 01 janvier 2008, consulté le 22 septembre 2020. URL : http://journals.openedition.org/ifha/1636 ; DOI : https://doi.org/10.4000/ifha.1636

Ce document a été généré automatiquement le 22 septembre 2020

(C)IFHA 


\title{
Dinzelbacher, Peter, Das Fremde Mittelalter. Gottesurteil und Tierprozess
}

\author{
Thomas Lienhard
}

1 Le livre que voici est passionnant; quant à savoir s'il est juste, c'est autre chose.

2 Il est passionnant d'abord par le corpus qu'il étudie, à savoir deux pratiques judiciaires médiévales dont tous les ingrédients contribuent à surprendre le lecteur contemporain. Surprise face à l'ampleur du phénomène d'abord, puisqu'en 1166, soit moins d'un demisiècle avant l'interdiction de cette pratique par le Saint-Siège, les pipe rolls dénombrent encore quelque 600 cas de jugements de Dieu ; face à ses modalités, puisqu'on se trouve en présence d'accusés sommés de porter du fer brûlant, de plonger les bras dans des chaudrons bouillonnants, mais aussi d'avaler du pain sans s'étouffer ou de communier sous les deux espèces ; face aux chefs d'accusation, puisque par-delà les principaux crimes de sang, c'était également l'accusation d'hérésie ou celle de négligence de parents vis-à-vis de leurs enfants qui pouvaient conduire à cette pratique ; enfin face à l'identité de ceux qui faisaient l'objet de pratiques judiciaires, puisque P.D. consacre un ample chapitre aux procès intentés à des animaux à la fin du Moyen Âge, avec plaidoiries publiques, recours à des avocats pour défendre les accusés, préavis de sept jours pour que les bêtes puissent méditer le jugement, et possibilité de lettres de grâce comme celle qui fut accordée par Philippe II de Bourgogne pour deux troupeaux de cochons. C'est dire si nous avons affaire à une histoire totale.

3 Les mérites de l'auteur ne se limitent pourtant pas à un corpus bien choisi. Contrairement à une historiographie traditionnelle qui se contentait d'évaluer le caractère prémoderne, décadent par rapport au droit romain ou simplement horrible des jugements de Dieu, P.D. analyse minutieusement les modalités concrètes de ces pratiques, non par goût du morbide mais parce que cela fournit autant d'éléments d'explication. On apprend ainsi, considérations médicales à l'appui, tous les moyens possibles pour tricher lors d'une telle épreuve physique, ce qui fournissait aux organisateurs une marge de tolérance et favorisait la négociation ; on apprend également le coût financier de tels jugements, facteur répulsif pour les uns mais attractif pour les autres; on apprend enfin les écarts sociologiques dans l'application de 
ces jugements, puisqu'une roturière laïque et un grand ecclésiastique se voyaient appliquer des épreuves nettement différenciées. Par toutes ces facettes, le présent livre insère de l'Alltagsgeschichte dans la Verfassungsgeschichte, et l'enrichit ainsi considérablement.

L'ouvrage n'est cependant pas sans poser de nombreux problèmes. On passera rapidement sur l'habitude détestable consistant à fournir comme référence non pas des sources, mais des ouvrages de seconde main, obligeant ainsi le lecteur à un pénible travail de reconstitution pour obtenir toute information supplémentaire. En revanche, on sera plus gêné de constater que l'auteur, dans l'objectif louable de diversifier les types de sources, en vient à placer sur un même plan une donnée juridique extraite d'un écrit législatif, d'un récit hagiographique ou d'un formulaire, parfois sans même signaler cette hétérogénéité et a fortiori sans pondérer son interprétation en conséquence. Si l'on ajoute à cela le fait que les épisodes cités sont très courts et présentés en-dehors de leur contexte, on aboutit à un exercice fort stimulant, mais légèrement fastidieux, dans lequel le lecteur doit souvent refaire l'enquête lui-même.

Le point le plus critiquable réside pourtant dans les jugements de valeur qui ruissellent au fil des pages. On ne commentera pas ici l'anticléricalisme débordant de l'auteur, qui semble déplacé lorsqu'il tourne au plaidoyer du protestantisme face à ce qui est caractérisé comme les absurdités du catholicisme médiéval (quel intérêt ici ?). On s'attardera davantage, en revanche, sur l'opposition revendiquée entre un haut Moyen Âge qui, friand des jugements de Dieu, aurait donc jugé de manière absurde et un bas Moyen Âge qui aurait vu la renaissance de la raison dans le domaine judiciaire. Pour asséner de tels jugements contre une période altimédiévale longue d'un demimillénaire, il faudrait d'abord être certain de l'avoir bien comprise ; or P.D. néglige bien des éléments qui contribuent à donner sens aux pratiques qu'il étudie. Pour ne prendre ici qu'un exemple, il n'évoque pratiquement pas le public présent lors des ordalies ou des duels judiciaires. Or quand les sources offrent un indice sur les assistants à ces cérémonies, ceux-ci sont généralement nombreux, parfois convoqués sur place en qualité de témoins, et cela en un lieu qui est traditionnellement affecté à ces cérémonies et confère donc un caractère officiel à l'événement; si on ajoute à cela la forte impression psychologique produite par le spectacle d'une épreuve physique douloureuse, on comprend que l'objectif consistait avant tout à produire un événement dont l'existence ne pouvait plus être niée par la suite. Il s'agissait ainsi de forcer l'adhésion d'une communauté à une décision, pour éviter le prolongement des contestations et des conflits. Quant à savoir si le jugement était juste (appliquant une peine bien proportionnée, ou même punissant le véritable coupable), il s'agit là d'une préoccupation qui était non pas absente, mais secondaire dans la logique des législateurs du haut Moyen Âge. En ce sens, on peut approuver P.D. lorsque ce dernier considère que la logique judiciaire du (haut) Moyen Âge fut très différente de la nôtre ; il n'est pas légitime pour autant de qualifier cette époque d'irrationnelle, ni a fortiori de considérer qu'elle est retombée en enfance intellectuellement suite à l'installation des peuples germaniques, comme le fait l'auteur en recourant explicitement aux modèles issus de la psychologie de l'enfance.

6 Par moments, ce livre nous rend le Moyen Âge plus étranger qu'il ne le fut vraiment ; il faut le lire tout de même.

7 Thomas Lienhard (MHFA) 